\title{
Forecasting of Perspective Flotation Reagents on the Base of Structure Based Virtual Screening
}

\author{
Peter Solozhenkin $^{1}$, Olga Ibragimova ${ }^{2}$ \\ ${ }^{1}$ Federal state budgetary establishment of a science Research Institute of Comprehensive \\ Exploitation of Mineral Resources of the Russian Academy of Science (IPKON the RASci), Kryukovsky Tupik, 4, Moscow, 111020 Russia \\ ${ }^{2}$ University of Dodoma, Department of Mining and Mineral Processing Engineering, P.O.Box 259, Dodoma, Tanzania
}

\begin{abstract}
The molecular models of complexes of poorly studied mineral clusters and reagents in developing the principles of evaluation of forecasting in flotation reagent activity have been created and optimized by using Chem Bio 3D and ChemOffice2005 by Cambridge Soft with optimization by MM2. It is proposed to use structure based virtual screening (SBVS) and reduce enormous amount of chemical compounds to a more manageable number for synthesis and screening which could lead to potential flotation candidates. The metal tellurides and arsenic sulfides as poorly explored types of minerals have been investigated. HOMO, SOMO, LUMO and total energies, atomic charges and $s, p, d$-population were determined for the various compounds. The strategy of prognosis of collector activity evaluation (PCAE) has been proposed as a consistent approach to estimate the interaction between a collector and a mineral cluster to search the analogue of butyl xanthate. The relationship between PCAE and flotability has been established. Our results indicate that the lower PCAE the stronger the interaction between the collector and the mineral cluster. The binary complexes of various reagents on the mineral surface have been studied. It was shown that the lowest magnitude of PCAE was obtained for arsenopyrite with binary mixture of dibutyl dithiophosphoric acid and diethylaminoethyl xanthic acid that indicated the high chemical activity of the combination of reagents. Forecasting of perspective flotation reagents by screening of chemical compounds and theoretical results obtained from research can provide a basis for innovative technology in mineral processing.
\end{abstract}

Keywords: Molecular Modeling, Collector Activity Evaluation, Forecasting, Flotation

\section{Introduction}

Currently tens of millions organic compounds with various chemical structures have been synthesized. Tens of thousands of chemicals were either tested or suggested as flotation reagents. Sulfur-containing reagents are widespread collectors for sulfide flotation. Xanthates, dithiophosphates, dithiocarbamates and their derivatives are equally important. Although all of these compounds contain sulfur, the structure of molecules is rather different. Each compound has its specific physical and chemical properties. There is the interrelation between the spatial structure of a molecule and its chemical activity. However the most troublesome question for researchers remains the estimation of quantitative structure-property relationship. The knowledge generated in these studies and correlation established is extremely helpful in quick selection of compounds with desired properties as well as in synthesis of new reagents. Corporate and commercial libraries have the huge amount of information about organic compounds for screening. Nevertheless in practice it is not necessary to check the whole database of these libraries but information about compounds which have the high ability to react with mineral clusters should be taken into account.

There is a large number of approaches to choose the flotation reagents with desirable properties. Modern computational methods allow to find the way of visualizing a model of the molecule and understand the connection between the spatial structure and chemical activity. Molecular modeling has been intensively developed over the past ten years.
Significant research on computer modeling of oxhydryl reagents was carried out in India [1], [2]. The molecular structures of the various collectors were fully optimized in China using density functional theory (DFT) which offered an effective tool in the calculation of the properties and energies of the various collectors [3], [4]. Molecular modeling of sulfhydryl reagents was carried out in Turkey [5], [6], Finland [7] and Russia [8].

In a series of papers the authors have proven the effectiveness of using computer technology and chemical software to study the ore flotation [8]- [15]. It was proposed the new class of compounds with phosphorus (III) such as $\left(\mathrm{C}_{2} \mathrm{H}_{5}\right)_{2} \mathrm{PCS}_{2} \mathrm{H}, \quad\left(\mathrm{C}_{2} \mathrm{H}_{5}\right)_{2} \mathrm{PCOSH}, \quad\left(\mathrm{C}_{2} \mathrm{H}_{5} \mathrm{O}\right)_{2} \mathrm{PCS}_{2} \mathrm{H}$, $\left(\mathrm{C}_{2} \mathrm{H}_{5} \mathrm{O}\right)_{2} \mathrm{PCOSH},\left(\mathrm{C}_{2} \mathrm{H}_{5}\right)_{2} \mathrm{PCSOH}$ and $\left(\mathrm{C}_{2} \mathrm{H}_{5} \mathrm{O}\right)_{2} \mathrm{PCSOH}$ for platinum and osmium minerals. It has been established that the reagent $\left(\mathrm{C}_{2} \mathrm{H}_{5} \mathrm{O}\right)_{2} \mathrm{PCS}_{2} \mathrm{H}$ can be the prospective collector for the flotation of ores containing platinum and osmium minerals [12].Therefore, the present study is aimed at construction of molecular models of complexes of poorly studied mineral clusters and reagents in developing the principles of evaluation of forecasting in flotation reagent activity. The metal tellurides and arsenic sulfides as poorly explored types of minerals have been investigated. The knowledge obtained from research can provide a basis for innovative technology in mineral processing.

\section{Research Objectives}

The study was based on mineral models (flotation reagents), named mineral clusters (reagents), as their structures correspond to chemical formulas and the distance between different atoms corresponds to known tabulated data. Metal 


\section{International Journal of Science and Research (IJSR) \\ ISSN (Online): 2319-7064}

Index Copernicus Value (2013): 6.14 | Impact Factor (2014): 5.611

telluride clusters such as $\mathrm{Te}_{2} \mathrm{Pd}, \mathrm{Ag}_{4} \mathrm{Te}_{2}, \mathrm{AuAg}_{3} \mathrm{Te}_{2}$, arsenic minerals such as realgar, orpiment, lollingite and arsenopyrite have been studied. $\mathrm{C}_{5} \mathrm{H}_{10} \mathrm{OS}_{2}$ (BXA), $\mathrm{C}_{3} \mathrm{H}_{7} \mathrm{NS}_{2}$ (DMDTCA), $\quad \mathrm{C}_{7} \mathrm{H}_{15} \mathrm{NOS}_{2} \quad$ (DEAEXA), $\quad \mathrm{C}_{20} \mathrm{H}_{45} \mathrm{~N}_{2} \mathrm{PS}_{2}$ (DBAEDTPA), $\quad \mathrm{C}_{7} \mathrm{H}_{6} \mathrm{~N}_{4} \mathrm{~S} \quad$ (Tetrazol), $\quad \mathrm{C}_{8} \mathrm{H}_{10} \mathrm{O}_{2} \mathrm{PS}_{2} \quad$ ( DBDTPA) have been selected. BXA and DMDTCA have been established as standard reagents for estimation the effectiveness of organic compounds studied.

\section{Methods}

\subsection{Computational Methods}

In the present study computational modeling of minerals and reagents was performed using Chem Bio 3D and ChemOffice2005 by Cambridge Soft with optimization by MM2. MM2 energy-minimization is used to prevent a freely rotatable bond and calculate properties of organic molecular models. The semi empirical calculations were provided by MOPAC 2012 in vacuum [16] - [18]. Molecular structures of metal tellurides clusters were created. DTF approach was used to determine the optimal molecular structure and calculate atomic charge values, the compositions and energies of HOMO, LUMO and SOMO.

\subsection{Docking Approach}

Complex formations have been established with the aid of computational docking technique. The docking method is a search algorithm and a scoring function that predicts the preferable orientation of one molecule to a second to form a stable complex and estimate collecting activity of reagents. The approach has proved useful in identifying relevant candidates for several flotation applications [12] - [15].

\section{Results and Discussion}

\subsection{Molecular Geometry of Mineral Clusters}

The structural and optimized 3D models of metal tellurides and arsenic minerals are shown in Figure 1 and 2 (a, b, c).

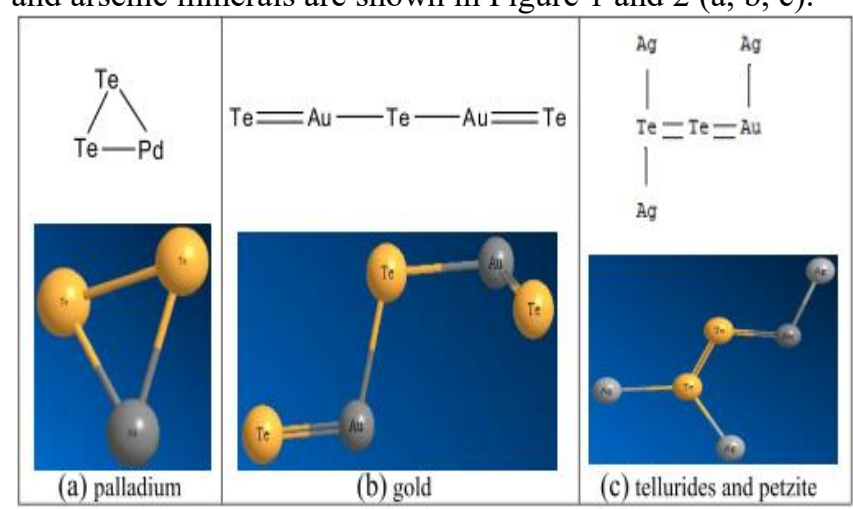

Figure 1: The structural and 3D models for palladium (a), gold (b) tellurides and petzite (c).

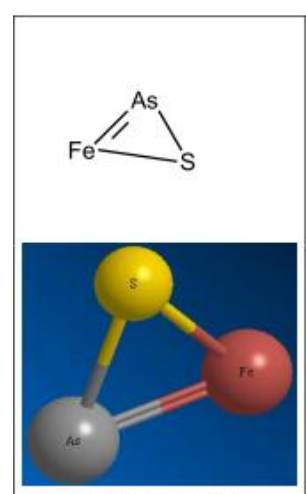

(a) arsenopyrite

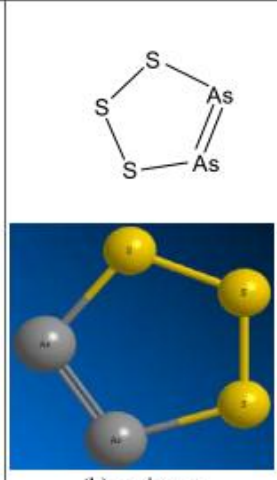

(b) orpiment

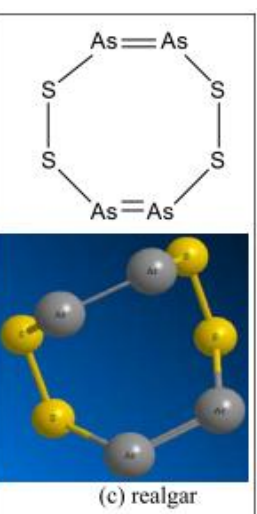

(c) realgar
Figure 2: The optimized structure and and 3D models for arsenic mineral clusters: arsenopyrite(a), orpiment(b), realgar(c).

The calculated Mulliken atomic charge values, the number of electrons, the theoretical dipole moments, the s, p, dpopulations for metal tellurides are given in Table 1, 2 and 3 respectively.

Table 1: Selected optimized parameters for studied clusters of metal tellurides

\begin{tabular}{|c|c|c|c|c|}
\hline Mineral Cluster & $\begin{array}{c}\text { Atom } \\
\text { № }\end{array}$ & Type & Charge & $\begin{array}{c}\text { № of } \\
\text { Electrons }\end{array}$ \\
\hline $\begin{array}{c}\text { Gold } \\
\text { Telluride } \\
\text { TeAuTeAuTe }\end{array}$ & $\begin{array}{l}1 \\
2 \\
3 \\
4 \\
5\end{array}$ & $\begin{array}{l}\mathrm{Te} \\
\mathrm{Au} \\
\mathrm{Te} \\
\mathrm{Au} \\
\mathrm{Te}\end{array}$ & $\begin{array}{r}-0.004261 \\
0.006642 \\
-0.017554 \\
0.032120 \\
-0.016948\end{array}$ & $\begin{array}{l}6.0043 \\
10.9934 \\
6.0176 \\
10.9676 \\
6.0169 \\
\end{array}$ \\
\hline $\begin{array}{l}\text { Palladium } \\
\text { Telluride } \\
\mathrm{Te}_{2} \mathrm{Pd}\end{array}$ & $\begin{array}{l}1 \\
2 \\
3\end{array}$ & $\begin{array}{l}\text { Te } \\
\text { Te } \\
\mathrm{Pd}\end{array}$ & $\begin{array}{r}-0.011770 \\
-0.011622 \\
0.023392\end{array}$ & $\begin{array}{l}6.0118 \\
6.0116 \\
9.9766\end{array}$ \\
\hline $\begin{array}{l}\text { Silver } \\
\text { Telluride } \\
\mathrm{Ag}_{4} \mathrm{Te}_{2} \\
\left(\mathrm{Ag}_{2} \mathrm{Te}\right)\end{array}$ & $\begin{array}{l}1 \\
2 \\
3 \\
4 \\
5 \\
6 \\
\end{array}$ & $\begin{array}{l}\mathrm{Ag} \\
\mathrm{Te} \\
\mathrm{Ag} \\
\mathrm{Te} \\
\mathrm{Ag} \\
\mathrm{Ag}\end{array}$ & $\begin{array}{l}0.108798 \\
-0.219688 \\
0.109279 \\
-0.213981 \\
0.107541 \\
0.108052 \\
\end{array}$ & $\begin{array}{l}10.8912 \\
6.2197 \\
10.8907 \\
6.2140 \\
10.8925 \\
10.8919 \\
\end{array}$ \\
\hline $\begin{array}{c}\text { Petzite } \\
\mathrm{AuAg}_{3} \mathrm{Te}_{2}\end{array}$ & $\begin{array}{l}1 \\
2 \\
3 \\
4 \\
5 \\
6\end{array}$ & $\begin{array}{l}\mathrm{Te} \\
\mathrm{Au} \\
\mathrm{Ag} \\
\mathrm{Te} \\
\mathrm{Ag} \\
\mathrm{Ag}\end{array}$ & $\begin{array}{l}-0.401090 \\
0.040381 \\
0.221043 \\
-0.215326 \\
0.124421 \\
0.230571\end{array}$ & $\begin{array}{l}6.4011 \\
10.9596 \\
10.7790 \\
6.2153 \\
10.8756 \\
10.7694\end{array}$ \\
\hline
\end{tabular}

Table 2: Theoretical dipole moments for metal tellurides

\begin{tabular}{|c|c|}
\hline Mineral Cluster & Dipole moment \\
\hline $\begin{array}{c}\text { Gold Telluride } \\
\text { TeAuTeAuTe }\end{array}$ & 0.669 \\
\hline $\begin{array}{c}\text { Palladium Telluride } \\
\mathrm{Te}_{2} \mathrm{Pd}\end{array}$ & 1.860 \\
\hline $\begin{array}{c}\text { Silver Telluride } \\
\mathrm{Ag}_{4} \mathrm{Te}_{2} \\
\left(\mathrm{Ag}_{2} \mathrm{Te}\right)\end{array}$ & 0.111 \\
\hline $\begin{array}{c}\mathrm{Petzite}^{\mathrm{AuAg}} \mathrm{Te}_{2} \\
\end{array}$ & 11.727 \\
\hline
\end{tabular}




\section{International Journal of Science and Research (IJSR) \\ ISSN (Online): 2319-7064}

Index Copernicus Value (2013): 6.14 | Impact Factor (2014): 5.611

Table 3: The s, p, d- populations for studied clusters of metal tellurides

\begin{tabular}{|c|c|c|c|c|}
\hline $\begin{array}{l}\text { Mineral } \\
\text { Cluster }\end{array}$ & $\begin{array}{c}\text { Atom } \\
\text { № }\end{array}$ & s-pop & p-pop & d-pop \\
\hline $\begin{array}{c}\text { Gold } \\
\text { Telluride } \\
\text { TeAuTeAuTe }\end{array}$ & $\begin{array}{l}1 \\
2 \\
3 \\
4 \\
5\end{array}$ & $\begin{array}{l}1.99874 \\
1.00302 \\
1.99912 \\
0.97705 \\
1.99917\end{array}$ & $\begin{array}{l}4.00552 \\
0.00799 \\
4.01843 \\
0.00818 \\
4.01777\end{array}$ & $\begin{array}{l}9.98235 \\
9.98265\end{array}$ \\
\hline $\begin{array}{c}\text { Palladium } \\
\text { Telluride } \\
\mathrm{Te}_{2} \mathrm{Pd}\end{array}$ & $\begin{array}{l}1 \\
2 \\
3\end{array}$ & $\begin{array}{l}1.91897 \\
1.91896 \\
1.80585\end{array}$ & $\begin{array}{l}4.09280 \\
4.09267 \\
0.00285\end{array}$ & 8.16791 \\
\hline $\begin{array}{c}\text { Silver } \\
\text { Telluride } \\
\mathrm{Ag}_{4} \mathrm{Te}_{2} \\
\left(\mathrm{Ag}_{2} \mathrm{Te}\right)\end{array}$ & $\begin{array}{l}1 \\
2 \\
3 \\
4 \\
5 \\
6\end{array}$ & $\begin{array}{l}0.89070 \\
1.95181 \\
0.89022 \\
1.95200 \\
0.89195 \\
0.89144\end{array}$ & $\begin{array}{l}0.00064 \\
4.26788 \\
0.00064 \\
4.26198 \\
0.00065 \\
0.00065\end{array}$ & $\begin{array}{l}9.99986 \\
9.99986 \\
9.99986 \\
9.99986\end{array}$ \\
\hline $\begin{array}{l}\text { Petzite } \\
\qquad \mathrm{AuAg}_{3} \mathrm{Te}_{2}\end{array}$ & $\begin{array}{l}1 \\
2 \\
3 \\
4 \\
5 \\
6\end{array}$ & $\begin{array}{l}1.95039 \\
0.96349 \\
0.78352 \\
1.95556 \\
0.87485 \\
0.77383\end{array}$ & $\begin{array}{l}4.45070 \\
0.02198 \\
0.02335 \\
4.25977 \\
0.00110 \\
0.02337\end{array}$ & $\begin{array}{l}9.97415 \\
9.97209 \\
9.99964 \\
9.97223\end{array}$ \\
\hline
\end{tabular}

The results obtained show that the d-population for these tellurides follows the order: palladium $(8.16891)<$ gold $(9.98235)<$ silver $(9.99986)$ with the decrease in dipole moments in the same order. The Mulliken atomic charge values, the number of electrons, the s, p, d-populations, and the dipole moments for arsenic clusters have been determined and their theoretical analysis shows that the increase in atomic charge is in the following order: lollingite, orpiment, realgar and arsenopyrite. The d-population for sulfur atoms is in the range $(-0.098580)-(-0.101404)$.

\subsection{Structure Based Virtual Screening (SBVS)}

Commercial libraries have collections of compounds readily available for screening. Online catalogs from Life Chemicals offer 2 million compounds and Zinc Corporation provides the information way above 13 million compounds. It is proposed to reduce enormous amount of chemical compounds to a more manageable number for synthesis and screening which could lead to potential flotation candidates. The computational docking techniques are a search algorithm and a scoring function that estimates collecting activity of reagents. The approach has proved useful in identifying relevant candidates for several flotation applications. Structure based virtual screening of chemical compounds is a fast and accurate method which help to identify potential leads suitable for further development.

SBVS has been built up from several steps:

1) The target and compound library preparation;

2) Reducing the amount of compounds;

3) Running the actual docking algorithms;

4) Post-processing and evaluation;

5) Ranking the results for assay by scoring function;

6) Cutting the non-relevant compounds;

7) Final Hit Selection

\subsection{Complex Formation with the aid of Computational Docking Technique}

Docking as a method of prediction the preferable orientation of one molecule to a second to form a stable complex, was harnessed to identify the relevant candidates for further flotation operations. The total energy and partial atomic charges have been determined to predict the collecting activity of reagents and their combinations. The strategy of prognosis of collector activity evaluation (PCAE) has been proposed as a consistent approach to estimate the interaction between a collector and a mineral cluster as a difference of total energy and sum of cluster energy and collector energy which is presented in Eq.1 as [12]- [15]:

$$
\mathrm{E}=\mathrm{E} \text { complex }-(\mathrm{E} \text { cluster }+\mathrm{E} \text { collector })
$$

The lower PCAE the stronger the ability of the collector to interact with the mineral cluster [13]- [15]. Although PCAE cannot play the role as an indicating physico-chemical parameter for the particle floated but allows to make some significant conclusions.

In the present study docking method was used to determine the optimal molecular structure of complexes between metal tellurides, arsenic mineral clusters and collectors. The chemical reaction between a sulfhydryl collector and a mineral is a frontier-controlled reaction; it means a collector transfers its HOMO electrons to a metal atom on the mineral surface to form a normal covalent bond. Additionally, if a metal atom has richly d-orbital electrons and a collector has the electron-accepting ability, the metal atom can transfer some of its d-orbital electrons to the LUMO of the collector to form back donation covalent bonds. The structural and geometrical models of the complex of arsenopyrite cluster with three molecules of butyl xanthate attached to iron atom are shown in Figure 3. The calculated PCAE data for various arsenic minerals clusters and BX are given in Table 4.

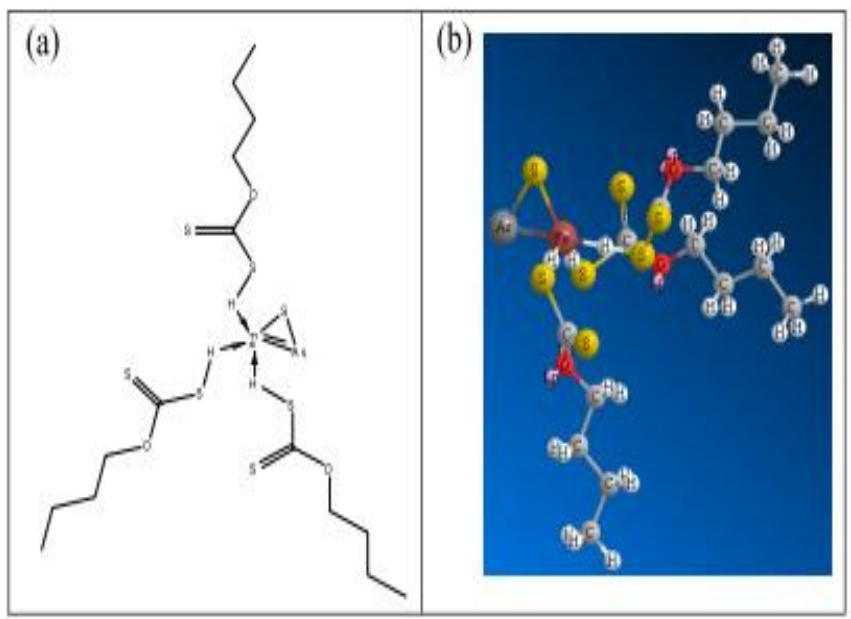

Figure 3: The structure (a) and 3D model (b) of arsenopyrite cluster complex with BX. 


\section{International Journal of Science and Research (IJSR) \\ ISSN (Online): 2319-7064}

Index Copernicus Value (2013): 6.14 | Impact Factor (2014): 5.611

Table 4: Calculated PCAE for arsenic mineral clusters and Butyl xanthate $(\mathrm{BX})(\mathrm{eV})$

\begin{tabular}{|c|c|c|c|c|}
\hline \multirow{2}{*}{$\begin{array}{c}\text { Mineral } \\
\text { cluster }\end{array}$} & \multicolumn{4}{|c|}{ Energy, eV } \\
\cline { 2 - 5 } & Complex & Mineral & Collector & PCAE \\
\hline 1 & 2 & 3 & 4 & $2-(3+4)$ \\
\hline $\begin{array}{c}\text { Arsenopyrite } \\
\text { FeAsS }\end{array}$ & -4899.67 & -700.39 & -1397.70 & -6.18 \\
& & & -1397.70 & \\
\hline Lollingite & -5498.39 & -1299.99 & -1397.70 & \\
FeAs & & & -1397.70 & -5.30 \\
\hline Orpiment $_{\text {As }} \mathrm{S}_{3}$ & -4981.66 & -787.30 & -1397.70 & \\
\hline Realgar $_{\text {As }} \mathrm{S}_{4}$ & -5415.28 & -1222.20 & -1397.70 & -1.26 \\
& & & -1397.70 & \\
& & & -1397.70 & \\
\hline
\end{tabular}

Table 4 indicates the value of PCAE was decreased from $+0.02 \mathrm{eV}$ for realgar up to $-6.18 \mathrm{eV}$ for arsenopyrite. The lower PCAE value the higher flotability of minerals. According to Table 4 the increase of flotability for these four arsenic minerals has to be followed as realgar, orpiment, lollingite and arsenopyrite which has a good correlation with the previous studies established [19].

\subsection{Metal Binary Complex Formation}

Xanthates are powerful collectors that are commonly used for recovering sulfide minerals. However, their selectivity is low without the use of additional reagents. It was shown that the highest magnitude of PCAE was obtained for stibnite and kermesite with butyl xanthic acid that indicated the weak flotability. In the contrary, the application of more selective diethildithiocarbamic acid $\left(\mathrm{C}_{2} \mathrm{H}_{5}\right)_{2} \mathrm{NCS}_{2} \mathrm{H}$ allowed to decrease the value of PCAE in 17 times. This reagent shows the strong collecting power in stibnite flotation [10].Therefore the preference of using the combination of reagents mentioned above appears to be at the significant value. It was also known that the recovery of gold with the aid of combination of reagents was increased and cynadation of tailings was avoided [20].

Collectors with amino group are known as the most prospective reagents for gold telluride flotation. Therefore the complex and optimized 3D model of gold telluride and the mixture of one molecule of DEAEXA and three molecules of DBAEDTPA attached to the gold atom were created and CRE values indicated that this parameter is lower for the mixture comparing to the individual reagents. It was shown that PCAE value for gold telluride $\mathrm{Au}_{2} \mathrm{Te}_{3}$ cluster with the mixture was $-302,5969 \mathrm{eV}$. Studies carried out on this subject also have shown that screening of chemical compounds can forecast the application of new dialkylaminosulfhydryl reagents for arsenic mineral flotation. On the base of computer modeling it was suggested the range of organic compounds which properties as proposal collectors for arsenopyrite flotation were predicted. We used virtual screening of chemical databases as a first and accurate method which helps to identify potential leads suitable for further development. Three commercially available databases were first screening for their collector like properties. Hit compounds that passed all tests were taken for molecular docking analysis. The hits obtained were screened for several filters. A set of hit compounds was selected and subjected to further analysis to avoid the falsepositive hits from virtual screening. The four virtual hits with the higher rank were identified as possible candidates for arsenopyrite flotation. The comparison in the PCAE value between $\mathrm{BX}$ and various perspective collectors attaching on the arsenopyrite cluster are given in Table 5.

Table 5: Calculated PCAE (eV) for various complexes

\begin{tabular}{|c|c|}
\hline Mineral + collector complex & PCAE, eV \\
\hline FeAsS + DMDTC & -2.1638 \\
\hline FeAsSStr3BX & -6.1865 \\
\hline FeAsSStr3DEAEX & -6.4376 \\
\hline FeAsSStrDBAEDTP & -6.1043 \\
\hline FeAsSStr2DEAEX+1DBDTP & -6.8385 \\
\hline FeAsSStr3Tetrazol & -4.7422 \\
\hline
\end{tabular}

From Table 3 it is evident that the PCAE value is decreasing in order as follows: DMDTCA, Tetrazol, DBAEDTPA, BXA, DEAEXA, Mixture DEAEX+DBDTPA. It has been established that the lowest PCAE is for the mixture of reagents. This combination of reagents has the PCAE value of $-6,8385$ which is less than the PCAE value for $\mathrm{BX}$ (relative difference equals $0.652 \mathrm{eV}$ ). On the base of calculating it was suggested to apply the combination of DEAEXA and DBDTPA for arsenopyrite flotation.

Figure 4 shows the optimized geometrical structure (a) and 3D model (b) of arsenopyrute complex with one molecule of DBDTPA and two molecules of DEAEXA.

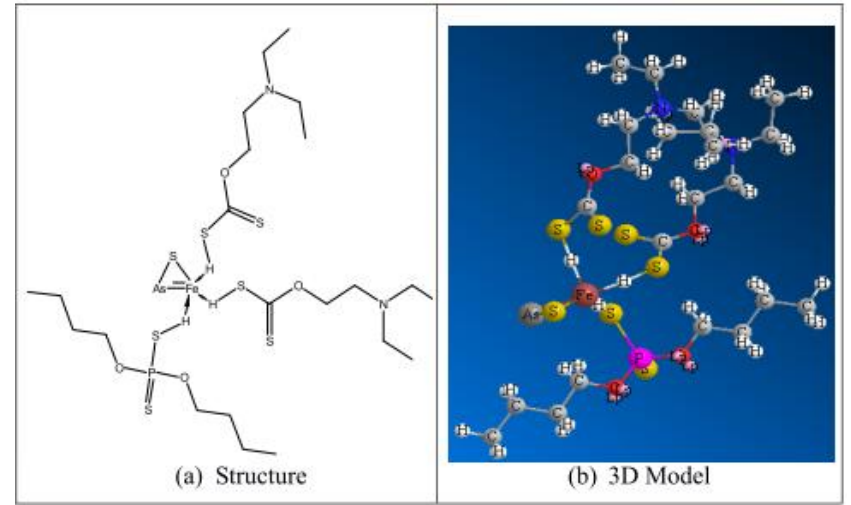

Figure 4: The structure (a) and 3D model (b) of the complex of arsenopyrite cluster and the mixture of DBDTPA + DEAEXA

\section{Future Scope and Implications of the Study}

Computational modeling and docking approach can find a reagent molecule which would interact with a mineral cluster. This is the best way to predict the structure of the intermolecular complex formed between a mineral and a collector to forecast the prospective reagents for flotation operations. 


\section{International Journal of Science and Research (IJSR) \\ ISSN (Online): 2319-7064}

Index Copernicus Value (2013): 6.14 | Impact Factor (2014): 5.611

\section{Conclusions}

The molecular models of complexes of poorly studied mineral clusters and reagents in developing the principles of evaluation of forecasting in flotation reagent activity have been created and optimized. The HOMO, SOMO, LUMO energies, atomic charges, s, p, d-population on orbitals has been determined.

The structure based virtual screening (SBVS) has been proposed to reduce the amount of chemical compounds available to a more manageable number for synthesis and screening which could lead to potential flotation candidates.

The strategy of prognosis of collector activity evaluation (PCAE) has been suggested as a consistent approach to estimate the interaction between a collector and a mineral cluster. The lower PCAE the stronger the interaction between the collector and the mineral cluster.

Studies carried out on this subject also forecast the application of new dialkylamino sulfhydryl reagents for ore flotation. There is a strengthening effect of binary mixture of reagents on flotability of sulfide minerals which mechanism of interaction has been established and technological properties have been forecasted.

Forecasting of perspective flotation reagents by screening of chemical compounds and theoretical results obtained from research can provide a basis for innovative technology in mineral processing.

\section{References}

[1] Pradip \& Beena Rai. Molecular modeling and rational design of flotation reagents. International Journal of Mineral Processing, Vol.72, pp. 95-110, 2003

[2] Beena Rai. Molecular modeling for the design of novel performance chemicals and materials. Boca Raton(USA):CRC Press, Taylor \& Francis Group, 319 p, 2012

[3] G.Y. Liu, H. Zhong, T.G. Dai, L.Y. Xia. Investigation of the effect of N-substituents on performance of thionocarbamates as selective collectors for copper sulfides by ab initio calculations, Mineral Engineering, Vol 21, pp 1050-1054, 2008.

[4] G.Y. Liu, H. Zhong, L.Y. Xia, S. Wang, T.G. Dai Effect of $\mathrm{N}$-substituents on performance of thiourea collectors by density functional theory calculations, Transactions of Nonferrous Metals Society of China, Vol 20, No 4, pp 695-701. 2010

[5] M. Yekeler, H. Yekeler. Reactivities of some thiol collectors and their interactions with $\mathrm{Ag}^{+}$ion by molecular modeling, Apply Surface Science. 236, pp. 435-443, 2004.

[6] T. Güler, C. Hiçyilmaz, G. Gökağaç, Z. Ekmeçi, Adsorption of dithiophosphate and dithiophosphinate on chalcopyrite, Minerals Engineering, Vol 19, pp 62-71, 2006

[7] M. Porento, P. Hirva P. (2004) A theoretical study on the interaction of sulfhydryl surfactants with a covellite
(001) surface., Surface Science. 2004, 555, pp. 75-82, 2004

[8] P.M. Solozhenkin, Ecological problems-new tendency of rational usage of gold-antimony ores and concentrates. VINITI.Scientific and technical acpects of environmental protection. Survey.M, №2, pp1-120, 2006

[9] P.M. Solozhenkin. Research of interaction of prototypes of minerals with solutions of reagents quantum chemical method, Proceeding 16-th Conference on Environment and Mineral Processing, 7-9 June, 2012, VSB-TU OSTRAVA, Czech Republic. Part II.pp.207212, 2012

[10]P.M. Solozhenkin, O.I. Solozhenkin, S. Krausz Prediction of Efficiency of Flotation Collectors Based on Quantum Chemical Computations. Books of Abstracts. XXVI International Mineral Processing Congress, 2012. New Delhi, India, September 24-28, vol. 2, p. 638, 2012

[11]P.M. Solozhenkin, Quantum-chemical and moleculardynamic aspects of forecasting of properties of collectors of metals from productive solutions of nonferrous metals, Works of the international scientific symposium «Week of the miner 2012», The collection of articles, Separate release of the mountain-information analytical bulletin (scientific and technical magazine) M: Publishing house «Mountain book», NOR1-632. pp.431-455, 2012

[12]Peter M.Solozhenkin, Igor P.Solozhenkin, Sanda Krausz. Predict flotation of minerals of elements of platinum group according to molecular modeling and creation of innovative technology in processing of ores of precious metals. Books of abstracts. XXVII International Mineral Processing Congress, Santiago, Chile, October 20-24, vol.1, p 240, 2014

[13] P.M.Solozhenkin, Sanda Krausz, O.I.Ibragimova. Modified fatty acids as flotation reagents for non-sulfide ores: molecular modeling for prognosis of collector activity evaluation. Proceeding of XVI Balkan Mineral Processing Congress, Belgrade, Serbia, June 17-19, pp.327-333, 2015

[14]Peter Solozhenkin, Olga Ibragimova. Molecular modeling as an approach for flotation reagents selection. International Journal of Science and Research.Vol.4, Issue, 9, pp.1883-1887, 2015

[15]P. Solozhenkin, O. Ibragimova. Molecular Modeling and Docking Approach for Predicting Potential Flotation Reagents, Proceeding of the World Congress on Mechanical, Chemical and Material Engineering, Barcelona, Spain, July 20-21, pp.3041-3148, 2015

[16] Roshupkin. Space modeling of molecular compounds Chemistry: methods of teaching.№1.pp.46-58, 2004

[17]M.E. Soloviev, M.M. Soloviev. Computational chemistry. SOLON Press, 536p, 2005

[18]Khel't'e. Molecular Modeling: Theory and Practice.Moscow; Binom. Laboratory of Knowledge, 319 p, 2013

[19] Smith L, K.J. Davey, L.Forbes, W.J. Brickard. (2013) Fundamental studies of the Flotation of Realgar and Orpiment. Proceeding of XV Balkan Mineral Processing Congress (edited by Nishkov I., Grigorova I., Mochev

\section{Volume 4 Issue 11, November 2015}


D.), June 12-16, Vol. 1, 305-312, Sozopol, Bulgaria, 2013

[20] Pshennikov A, N. Voyloshnikova, P. Solozhenkin, N. Nekhoroshev.(2014). The use molecular modeling for process development Au-Bi- Fe3O4 - ores. Books of Abstracts. XXVII International Mineral Processing Congress, Santiago, Chile, Oct. 20-24, vol. 2, p. 418, 2014.

\section{Author Profile}

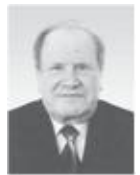

Peter Solozhenkin is an outstanding scientist, who received the MS degree in Mineral Processing Engineering from the Irkutsk Mining Metallurgical Institute in 1957.During 1975-1989 he was a VicePresident of the Tajik Academy of Science. Now he is working in IPCON, Russia. His research interests are devoted to Complex Exploitation of Mineral Resources and Computer Modeling of Flotation Processes. He is the author of 17 books, several hundreds of papers, patents and articles.

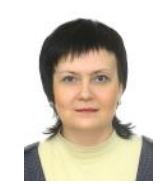

Olga Ibragimova received the MS degree in Mineral Processing Engineering from the Moscow Institute of Steel and Alloys, Russia in 1986. During 1986-1994 she stayed in Ore Dressing Laboratory, Institute of Chemistry, Tajik Academy of Science to study the phenomenon of the effect of combination of sulfur-containing collectors on non-ferrous ores flotation using spectroscopic methods. Then she has been an associate professor at the Samara State Technical University, Russia, over the past 15 years. Presently, she is teaching at the University of Dodoma, Tanzania. Current research interests include Computer Modeling of Chemical Compounds and Processes. 